\title{
The Traditional Culture of Modern Environmental Design Idea
}

\author{
Ling $\mathrm{Xia}^{1},{ }^{*} \mathrm{Xu} \mathrm{Li}{ }^{1}$ \\ ${ }^{1}$ Architecture and Urban Planning College, Southwest University for Nationalities, Chengdu, \\ Sichuan, China \\ ${ }^{*}$ Corresponding Author: Ling Xia
}

Keywords: Traditional culture, Modern environmental art design, Cultural integration

\begin{abstract}
As the buildings filled with the Chinese traditional art essence were gradually removed, the modern design architectures have become the main body of the city. Under the trend of globalization, the traditional ideas of environmental design have changed. The architects should absorb the foreign advanced experience and put the traditional Chinese culture into the architecture design to build the perfect combination of tradition and modernization. This paper expounds the reasons for adding the traditional culture idea to the modern environmental art design as well as the methods of how to achieve the perfect integration of traditional culture and modern elements in modern environmental design to provide reference for the architects in the new era.
\end{abstract}

\section{Necessity of Combination of Traditional Culture and Modern Environmental Art Design}

In the background of globalization, China is also full of the pursuit of modernization. Western culture, industrial technology and aesthetic ways not only greatly impact the Chinese traditional cultural norms, but also bring about the localization of environmental art in the context of globalization. With the increasing frequency of foreign designers in China, the designs of the international level have gradually been applied in our life. It also leads to the domestic designers of the two design concepts. The development of modern environmental art design in the west is mainly industrialized civilization. Its development level is more complete, from the decorative materials. Production processes of the design philosophy are in a leading level. In western modern environmental art design, the designer of the metal materials, such as the precise grasp of the external performance of the western culture. Based on the Western tradition of material and spiritual civilization, the design of landscaping, public facilities often stress the western humanistic care.

Philosophers believe that cultural spirit is the intrinsic reason for promoting cultural history. Chinese traditional ideology and culture, such as "harmony between man and nature", "the identity about the matter and me" advocate the theory of yin and yang to reconcile and balance of things and pursue the internal spirit and external beauty of coordination. It also reflects the Chinese culture in the face of the new things of the outside world. With the value of traditional culture in the thought of the continuation, in grinding to make the traditional culture shinier. From a national perspective, the construction of the traditional culture is no doubt the external display of China's long history of deep inside a reflection of the external. For example, a series of Chinese elements designs of the Beijing Olympic Games make friends from all over the world feel fresh and new. From the appearance of the bird's nest ceramic texture, to the design of the Chinese style pane, every detail of the traditional history of the Chinese people are shocked by the Chinese civilization. Modern environmental art design is the traditional criticism and innovation, designers through more rigorous and effective way to meet the aesthetic requirements. The connotation can also improve the effect of the design of modern art and external appearance.

\section{Origin and Charms of Chinese Traditional Cultural Elements}

Environment art is the epitome of modern technology development and cultural progress. It is also the way of modern civilization and historical culture. In order to achieve the harmony and unity 
of modern environment art and nature, it is necessary to have a deep understanding of Chinese traditional culture.

Origination of Chinese Traditional Cultural Elements. As one of the four ancient civilizations, China's traditions have many deep meanings. The vast expanse of land, the similarities and differences between the rulers of culture and regional differences, as well as the inclusion of other cultures create a variety of design styles. From the south to the north of the bridges miles, from the southeast coast to the magnificent desert of Gobi, natural human elements provide unlimited potential for the designers in the design and the use of these elements also requires the designer through their own self-cultivation and deep design skills to grasp the inherent spirit and essence and cultural origin. Clouds of traditional Chinese elements, its shape source in natural clouds, peaceful and smooth is the spirit within, and this kind of spiritual pursuit from farming community to pray for good weather the original desire. Therefore, the real art design is the need for a full understanding of the culture of the designer, in the form of the basis of the interpretation of its cultural origin, the Chinese classical culture in the humanistic spirit and the national emotion and the art of grafting, realize the idea in the works. Therefore, it also puts forward higher requirements for designers, which requires designers expanding their horizons to find accurate and fresh inspiration and learn to use traditional culture in the modern environment art design innovation.

Cultural Atmosphere of Chinese Traditional Architectures. Chinese traditional architecture is well known for its fine and charm. The corner, the roof cornices, diversification, and other points in the architectures have a strong visual impact and appeal. In addition to the decorative effect, these rich and exquisite architectural also have the use function, such as horse head wall, palace of brackets, garden leaking windows, etc. Beijing the Imperial Palace construction group is the most representative of the collection of practical and artistic beauty as one of the ancient architectural art. In the layout it shows obvious symmetrical structure, the inside of the former courtyard sleep after the rational thinking. Color region division and full integration of the respect for the ancient culture of yin and Yang five elements said that the building body is divided into inner and outer court, and use the earth represents the yellow roof. According to the theory of the five elements of fire immature soil selection, the architects selected the red palace pillars. Flower window with a swastika pattern, wheels and money style are telling the charm of Chinese civilization with a silent language from the art form and cultural connotation of penetration.

\section{Applications of Chinese Traditional Cultural Elements in Modern Environmental Art Design}

The modern environmental art design has the soul after absorbing the traditional elements. The traditional culture has gained more opportunity to display. In the contemporary context, with the liberation of the people's minds, the Chinese people's aesthetic is different from the past. The use of traditional culture is based on the personal idea of the designer from the form of expression, the display of the environment to the meaning of the embodiment. Part of the modern works expresses the deep meaning by the traditional elements. For example, the four carved typical Chinese traditional art add the smart feelings for the heavy sense of traditional buildings. Xiangshan Hotel draws the lessons of the traditional space layout, study the layout of natural landscape vegetation, and create a harmonious cultural atmosphere. This combination of traditional elements and modern civilization promote the interaction between the East and the west to a great extent. It is the design concept and the progress of thinking.

Chinese traditional environmental design emphasizes the layout of Feng Shui, focusing on the overall harmony of the United States. In the design, mostly through the implicit way to show the simple and solemn sense of history, with a clever layout shows the designer's profound cultural heritage. For example, in the design of Beijing Xiangshan Hotel, Bei Yuming learned Suzhou garden design principle, using the traditional garden in stacked stone focused, flowers and moral technique, outstanding literati impressionistic characteristics, to draw the poetry theme in a stack of flowers and trees and stones add freehand traditional idea. At the same time into the western philosophy, atriums shared space to use them. In building materials and design reference dwellings 
processing environment, rocks and trees to make way for the very good embodies the principle of design and the environment. The implementation of these architectural concepts makes tourists swim the product such as poetry as well as to appreciate a painting, a reflection of the lakes natural harmonious beauty in the urban environment in rare waterside pavilions. So the traditional culture in the design of environmental art is not only the external form, but also the adoption of the thought and the integration of the modern and traditional culture.

\section{Collision of Traditional Cultural Ideas and Modern Environmental Art Design}

Under the influence of human factors and modern thoughts, part of the environmental art design works appeared in the worship of the foreign culture and mechanically to seek external similarity. Some architects ignore the internal connection, regardless of the use of the phenomenon of local elements. We should deeply realize that Chinese traditional culture originated from the history of the millennium, is rooted in the deep thought of the mark, which also resulted in the different ideas of Western ideas. So it takes a long time to realize the integration of cultural ideas. The lack of elements of traditional Chinese culture is produced in the evolution of the history, classics year accumulated to form the fixed shape, will disagreements and modern philosophy, directly reflected in the cultural exchange is not smooth, in actual use will naturally not compatible, the disharmony will lead to beauty. Culture develop need constantly to absorb the strengths from all directions, but any culture develop need material carrier, in the economically developed society, environmental art design products as a combination of material and spiritual civilization. This requires the designer in style on the basis of try to implication of into the art and design, without having to adhere to form and should have global view, such as rockery, road ecological landscape of the extension is in the art form of simulation, and blind, bend angle design is the embodiment of Confucian, interleaving so formed by the fusion of design is quite modern and traditional culture meaning. Clouds, dragons, Chinese red characteristic patterns and colors in modern landscape art with using and steel sculpture use collocation. Architects should focus on the details, integrate the elements of profound Chinese culture and art design to achieve a reasonable transformation, so that the perfect combination of modern and traditional. This is a big challenge in the design of modern environmental art for the architects.

Nowadays, the demands of people for the spiritual world have become more and more obvious. It is a problem needing resolve that how to satisfy the spiritual needs of the regional traditional culture and how to make the people who are in one of them can enjoy the modern comfortable living conditions. It is a difficult problem to be discussed that how to balance the contradiction and unity in our design practice. Two kinds of different results are caused by the rise of the design idea of the national traditional elements. The encouraging is that this kind of thought can promote the designers to explore the design style of the nation, and form the unique design style and design idea of the traditional culture. On the other hand is to imitate the metaphysics of traditional elements, too simple form of imitation. With upgrading of the importance of traditional culture, ancient town tourism is booming. Driven by economic interests, some antique modern buildings, modern atmosphere dilute the ancient town of the original historical significance, hindered the development of Chinese culture, spend the public enthusiasm for tracing the source of the traditional culture, causing the loss of traditional culture.

\section{Key Points of the Integration of Chinese Traditional Cultural Ideas and Modern Environmental Art Design}

Principles of Integration. First, architects should avoid the imitation of the forms of the cultural symbols. The external form of the design in traditional elements is based on growing on the cultural soil and any fine art form must be in for the national culture and spirit background to shine, similarly profound connotation also need with each other can be realized, so the prior to the use of cultural elements need investigation and research on the elements of cultural background. Second, architects should flexibly use the traditional culture of spiritual connotation and cultural origin in 
the art design. They should refine the essence of the traditional elements, understand the actual needs of people, and compare the characteristics of the times to select the appropriate entry point.

Innovation of Integration. The continuous improvement of culture and art is the fundamental driving force to maintain the vitality of the design. Therefore, in the modern environmental art and traditional culture of mutual integration designers should be inclusive, innovation, and find the charm of traditional culture and get development vitality under the stimulation of modern art. First, architects should pay attention to the integration of ancient and modern, make full use of modern technology resources, integration of ideas to achieve the traditional design in the difficult part. Nowadays, social ideology and thinking mode and the past have been greatly changed, require designers to accurately grasp the context of the development of the times, grasp the law of the changes of social ideology, so as to find a way to match the design of the people. Second, designers should be rooted in the nation's excellent culture, pay attention to the combination of Chinese and western. Since modern times, the West in science and technology, economy and other aspects of the world's development, while the cultural collision is conducive to the deep cultural exchanges between the two, its advanced design concepts and technology can be closer to the modern way of life, it is worth learning. Third, designers should be given the spirit of innovation and have the courage to try to achieve the innovation of the traditional culture. Based on the feasibility analysis of innovative ideas and the understanding of the environmental art aesthetics, the practical function of modern environmental art design is embodied by the aesthetic values of traditional culture.

\section{Conclusion}

Chinese traditional culture inheritance cannot be the step-by-step imitation, but the comprehensive understanding from the external form to the connotation in the modern environmental art design. Designers should learn to treat the traditional culture in the long run and from the development perspective and coordinate the relationship between modern thought and traditional culture. At the same time, the designers should be targeted to integrate the national regional culture into the modern environmental art design to obtain the public's identity and sense of belonging, reflecting the social value and cultural value of modern environmental design art.

\section{References}

[1] Feng Yuneng, Reference of Traditional Academic Landscape for Landscape Construction of Modern Campuses, Journal of Anhui Agricultural Sciences, 2011, 3(7):15-17.

[2] Zhou Wei, Research on the Application of Chinese Traditional Culture Art Elements in Modern Graphic Design, English on Campus, 2015(4):254-255.

[3] Li Li, The Traditional Chinese Architecture and Modern Environment Art Design, Wuhan University of Technology, 2008.

[4] Li Zelin, The Application and Research of Chinese Traditional Cultural Elements in Modern Decorative Art Design, Harbin University of Science and Technology, 2013. 